\title{
CLINICAL IMPACT OF NUTRITIONAL STATUS AND ENERGY BALANCE IN ELDERLY HOSPITALIZED PATIENTS
}

\author{
S. ALLEPAERTS ${ }^{1}$, F. BUCKINX ${ }^{2}$, O. BRUYÈRE ${ }^{2,3,4}$, JY. REGINSTER $^{2,4,5}$, N. PAQUOT $^{6}$, S. GILLAIN $^{1}$ \\ 1. Geriatric Department, CHU of Liège, Liège, Belgium; 2. Division of Public health, Epidemiology and health Economics, University of Liège, Liège, Belgium; 3. Department of \\ Motricity Sciences, University of Liège, Liège, Belgium; 4. WHO Collaborating Center for Public Health Aspects of Musculoskeletal Health and Aging, University of Liège, Lìge, \\ Belgium; 5. Chair for Biomarkers of Chronic Diseases, Biochemistry Department, College of Science, King Saud University, Riyadh, Kingdom of Saudi Arabia; 6. Department \\ of Diabetes, nutrition and metabolic diseases, CHU of Liège, Belgium. Corresponding author: Sophie Allepaerts, University of Liège, Geriatric Department, CHU - NDB, Rue de \\ Gaillarmont, 600,4032 Chenee, Belgium, Tél : +32436793 93, E-mail : sallepaerts@ @ chuliege.be
}

\begin{abstract}
Objectives: This study aimed 1) to assess the nutritional status of patients hospitalized in a geriatric ward using the recent Global Leadership Initiative on Malnutrition (GLIM) criteria, 2) to determine the balance between the energy intake (EI) with an enriched diet and the energy requirement (ER) using indirect calorimetry, and 3) to assess whether undernutrition is associated with 1-year outcome. Design: This is a prospective crosssectional study. Setting: This study was performed in a geriatric unit. Participants: Patients of this geriatric unit were eligible for the study if they agreed to participate and if they did not meet the exclusion criteria (presence of malignant tumour, uncontrolled heart or renal failure, thyroidal disease, uncontrolled sepsis, oedema of the lower limbs, wearing of a pacemaker, biological thyroid dysfunction and inability to perform walking tests). Measurements: Rest energy expenditure (REE) was measured by indirect calorimetry within the week of hospitalization. Total energy expenditure (TEE) was obtained by multiplying REE by a physical activity level coefficient and energy expenditure that was related to thermogenesis (i.e., $10 \%$ of the total amount of energy ingested over $24 \mathrm{~h}$ ) was added. Food intake was measured over a 3-day period. Undernutrition was defined using MNA and the criteria of the GLIM leadership. Clinical outcomes included 1-year institutionalisation and mortality. Results: Seventy-nine patients $(84.9 \pm 5.3$ years) were included. A total of 21 (26.6\%) patients were found undernourished. REE was $1088 \pm 181 \mathrm{kcal} /$ day $(17.8 \pm 2.9 \mathrm{kcal} / \mathrm{kg} /$ day $)$ and TEE was $1556 \pm 258 \mathrm{kcal} /$ day $(25.4 \pm 4.2 \mathrm{kcal} / \mathrm{kg} / \mathrm{day})$. Weight-adjusted REE and TEE were higher in undernourished patients compared to those well-nourished $(19.8 \pm 3.1 \mathrm{vs.} 17.1 \pm 2.6 \mathrm{kcal} /$ day and $28.4 \pm 4.5 \mathrm{vs} .24 .4 \pm 3.7 \mathrm{kcal} / \mathrm{day})(\mathrm{p}<0.05)$. The lower was the Body Mass Index (BMI), the higher was the energy needs $(\mathrm{p}<0.01)$. EI was significantly greater than energy requirements (difference requirements - intake with enriched diet $=-354 \pm 491 \mathrm{kcal} / \mathrm{day}$; $\mathrm{p}<0.0001$ ). This difference did not depend on BMI ( $\mathrm{p}=0.82)$, appendicular skeletal mass index (ASMI) $(\mathrm{p}=0.63)$, or the presence of undernutrition ( $\mathrm{p}=0.33$ ). At 1-year follow-up, $15(19 \%)$ patients died and $20(25.6 \%)$ were institutionalized. On multivariable analysis, male gender $(O R=5.63 ; p=0.015)$ and undernutrition $(O R=7.29 ; p=0.0043)$ emerged as independently associated with death. On multivariable analysis, only ASMI (OR $0.59(0.35-0.99)$, $\mathrm{p}=0.044)$ and activities of daily living (ADL) (OR $1.14(1.00-1.30), \mathrm{p}=0.043)$ were significantly associated with institutionalization. Conclusions: Undernutrition as assessed by the GLIM criteria remains common in elderly patients hospitalized in a geriatric unit and is associated with increased 1-year mortality but not with institutionalization. Energy requirements are higher in undernourished patients and in patients with a low BMI. Enriched energy intakes could sufficiently cover the energy needs of this population.
\end{abstract}

Key words: Energy expenditure, energy intake, hospital, indirect calorimetry, elderly.

\section{Introduction}

Meeting the diet and nutrition requirements of older people is crucial to promote healthy aging and quality of life (1). However, food intake and energy intake decrease with ageing (2). Older people eat more slowly, smaller meals and fewer snacks between meals compared to younger adults (3). This decrease in dietary intakes (low energy intake) associated with a decreased appetite has been described as «anorexia associated with ageing» and predisposes to undernutrition (4, 5). Mechanisms are not well understood but include a range of physiological, psychological and social factors that influence appetite and food consumption. Poor clinical prognosis, impaired functional status, longer hospitalization, increased in morbidity and mortality have been reported as the major consequences of undernutrition among hospitalized elderly patients (6). Although measurement of undernutrition varied depending on the hospital setting and method of nutritional assessment, its prevalence in acute care conditions was reported to range from $20 \%$ to $70 \%(2,7,8)$. Awareness on malnutrition among hospitalized elderly is crucial to provide optimal care as its prevalence continues to increase across the world (9). Moreover, elderly patients currently hospitalized with multiple diseases are much older than those described in published reports (10). In addition, many elderly patients are subject to transient phases of acute stress that may affect their energy requirements (11), Obtaining the latest data on the prevalence of undernutrition in this population remains important, as it may provide insight into the extent to which this issue currently is still a burden to this population and how far nutritional care policies should be adapted $(12,13)$. Numerous nutrition screening and assessment tools exist Published online November 11,2020 , htrp://10.1007/s 12603-020-1527-9 
to identify patients at risk and diagnose undernutrition (9, 14). The recent Global Leadership Initiative on Malnutrition (GLIM) has been introduced to facilitate the comparison of the prevalence, interventions and consequences of malnutrition (15). In order to adequately feed these people (adapted enriched diet), knowledge of their energy requirements is essential. The energy requirement is defined as the amount of energy needed to match energy expenditure (EE). The decrease in EE with age due to both a reduction in resting (R) EE and physical activity may be accentuated in acute illness conditions (2). In addition, anorexia induced energy restriction tends to further decrease REE (4). Data on the EE during hospitalization of elderly patients are yet limited $(2,7,16)$. Most of them only included a small number of sick patients and none used the GLIM to assess undernutrition. To better manage and avoid undernutrition during the hospital phase of elderly patients, our department has set up an enriched diet adapted to each patient. It is not known whether our enriched diet meets energy requirements and has an impact on clinical results. This study aimed 1) to assess the nutritional status of patients hospitalized in a geriatric ward using the recent GLIM criteria, 2) to determine the balance between the energy intake (EI) with an enriched diet and the energy requirement (ER) using indirect calorimetry, and 3) to assess whether undernutrition is associated with 1-year outcome (institutionalization and mortality).

\section{Methods}

\section{Study Population}

The present study was conducted between September 2015 and October 2016 in the geriatric unit of the CHU of Liège, Belgium. Exclusion criteria were malignant tumour, uncontrolled heart or renal failure, thyroidal disease, uncontrolled sepsis, oedema of the lower limbs, wearing of a pacemaker, biological thyroid dysfunction and inability to perform walking tests. All measurements were made within the week after stabilization of their acute condition. The protocol was approved by the ethic committee of the university of Liège hospital under the number B707201524354. Informed consent was obtained for each patient.

\section{Geriatric assessment}

Subjects' functional limitations in activities of daily living (ADLs) were assessed by the Katz scale (17), a score ranging from 1 to 4 was attributed to each item depending on how independent the individual was when performing the activity. Higher scores (maximum 32) indicated higher dependence in ADLs. The presence of a cognitive disorder was defined by a score to Mini Mental State Evaluation (MMSE) (18) inferior to $23 / 30$ or by a previous diagnosis completed by a geriatrician or a neurologist. The mini Geriatric Depression Scale (GDS-4), which is composed of 4 items, was used to assess the emotional status of each individual. A score $\geq 1$ indicated a risk of depression (19). Morbidity was assessed by the Charlson index. The Charlson Comorbidity Index is a method of categorizing comorbidities of patients based on the International Classification of Diseases (ICD) diagnosis codes. Each comorbidity category has an associated weight (from 1 to 6 ), based on the adjusted risk of mortality or resource use, and the sum of all the weights results in a single comorbidity score for a patient. A score of zero indicated that no comorbidities were found (maximum score 37) (20). Presence of frailty was determined using the Edmonton scale (0-3: not fragile; 4-5: slightly fragile; 6-8: moderately fragile; 9-17: severely fragile) (21).

\section{Food intake}

Food intake was assessed over a 3-day period. The percentage of each meal and snack consumed was noted in a specific table. A dietician calculated the daily total calories intake (EI) using the Nubel food composition table, which contains the nutritional (calories and other nutrients) composition of 1400 foods (22). Enriched diet consisted of $2650 \mathrm{Kcal}$, with $92.4 \mathrm{~g}$ of protein, $132 \mathrm{~g}$ of lipid and $252 \mathrm{~g}$ of carbohydrate. To reach this goal, a homemade cream was distributed at $4 \mathrm{pm}$, it consisted of $260 \mathrm{Kcal}$ with $8 \mathrm{~g}$ of protein, $13.5 \mathrm{~g}$ of lipid and $26.8 \mathrm{~g}$ of carbohydrate and a soup before lunch and dinner with $140 \mathrm{Kcal}$ and $8 \mathrm{~g}$ of protein.

\section{Nutritional status}

Undernutrition was diagnosed according the GLIM criteria. A two-step approach for the malnutrition diagnosis was selected, first screening to identify "at risk" status by the use of the Mini nutritional Assessment (MNA) and second assessment for diagnosis of undernutrition (Glim 2019) (15). MNA test comprises a screening part followed by an assessment part. If the score obtained for the screening part was of 12 points or more on a total of 14 points, the subjects was classified as wellnourished and did not need to complete the assessment part. When subjects presented a screening score of 11 points or less, the assessment part had to be completed. The full evaluation was scored on 30 points. A score of 24 points or more indicated that the subjects was well-nourished, a score between 17 and 23.5 points indicates a risk of undernutrition and a score lower than 17 points indicates undernutrition (23). When the patient was at risk of malnutrition according the MNA, the GLIM criteria were applied for diagnosis of undernutrition. GLIM criteria for the diagnosis of undernutrition are the combination of at least one phenotypic and etiologic criteria. Weight loss ( $>5 \%$ within past 6 months, or $>10 \%$ beyond 6 months), reduced BMI ( $<22$ if $>70$ years), and reduced muscle mass (Appendicular Skeletal Muscle Index (ASMI, kg/m2) using BIA : $<7$ for males and $<5.7$ females) characterized the phenotypic criteria, whereas reduced food intake/assimilation ( $<50 \%$ of energy requirement $>1$ week, or any reduction for $>2$ weeks, or any chronic gastro intestinal condition that adversely impacts food assimilation or absorption) and disease burden/ inflammation (Acute disease/injury or chronic disease-related) served as etiologic criteria (15). 
THE JOURNAL OF NUTRITION, HEALTH \& AGING

Table 1

Relationship between REE, TEE, EI and BMI

\begin{tabular}{lcccccc}
\hline & $\begin{array}{c}\text { BMI < 18.5 } \\
\mathbf{n = 1 1}\end{array}$ & $\begin{array}{c}\text { BMI 18.6-22 } \\
\mathbf{n = 1 5}\end{array}$ & $\begin{array}{c}\text { BMI 22.1-24.9 } \\
\mathbf{n = 2 0}\end{array}$ & $\begin{array}{c}\text { BMI 25-29.9 } \\
\mathbf{n = 2 0}\end{array}$ & $\begin{array}{c}\text { BMI > 30 } \\
\mathbf{n = 1 3}\end{array}$ & p \\
\hline REE (kcal/day) & $949 \pm 178$ & $1006 \pm 128$ & $1073.5 \pm 168.7$ & $1209.5 \pm 187.6$ & $1126 \pm 121.8$ & 0.0004 \\
REE (kcal/kg/day) & $21 \pm 3.3$ & $19 \pm 2.2$ & $18.3 \pm 2.4$ & $17 \pm 2$ & $14.5 \pm 1.66$ & $<0.0001$ \\
TEE (kcal/day) & $1354 \pm 255$ & $1439 \pm 183.2$ & $1535 \pm 241.3$ & $1729.6 \pm 268.3$ & $1610 \pm 174.2$ & 0.0004 \\
TEE (kcal/kg/day) & $30 \pm 4.9$ & $27.1 \pm 3.1$ & $26.1 \pm 3.5$ & $24.2 \pm 2.9$ & $20.7 \pm 2.4$ & $<0.0001$ \\
EI(kcal/day) & $1708.7 \pm 529.9$ & $1947 \pm 483$ & $1895 \pm 504.5$ & $1967.7 \pm 551.8$ & $2030.7 \pm 265.7$ & 0.56 \\
EI (kcal/kg/day) & $37.3 \pm 10.1$ & $36.8 \pm 9$ & $32.3 \pm 8.5$ & $27.7 \pm 8.6$ & $26.4 \pm 5.1$ & 0.0013 \\
ASMI $\left(\mathrm{kg} / \mathrm{m}^{2}\right)$ & $6.6 \pm 1.9$ & $6.7 \pm 1.3$ & $8.1 \pm 1.7$ & $8.4 \pm 0.9$ & $8.9 \pm 0.9$ & $<0.0001$ \\
\hline
\end{tabular}

RRE: Rest Energy Expenditure; TEE: Total Energy Expenditure; EI: Energy Intake; Appendicular Skeletal Mass Index (ASMI)

\section{Energy requirements}

REE was measured in the fasting state using an open-circuit indirect calorimetry (Deltatrac II; Datex Instrument, Helsinky, Finland) on one of the days during which the 3-day food intake was recorded. A ventilated hood system was wheeled to the patient's room. The system was calibrated before each measurement in accordance with the manufacturer's instructions. With the patient in the supine position, a 40-L transparent Perspex hood was placed over the head and neck with a thin plastic apron providing a rough seal around the chest. To avoid acute stress that could invalidate the results, the measurements were begun only within the week of hospitalization. Recordings were made every minute for at least 40 minutes or until such time as a 20 -minute steady-state period was observed; the data were then averaged to represent REE. Total energy expenditure (TEE) was calculated by adding to the REE $10 \%$ for the thermic effect of food and by multiplying this value by 1.3 for the physical activity, corresponding to a minimal activity for an elderly hospitalized patient $(2,16,24$, 25).

\section{Muscle mass}

Muscle mass was measured by a validated multi-frequency bioelectrical impedance analyser (BIA), (Biocorpus RX 4000 Body composition analysis). This non-invasive and easy method estimates the volume of fat and lean body mass based on the relationship between the volume of a conductor and its electrical resistance. Volunteers were lying in a bed and tactile electrodes were placed at 8 points on the body. ASMI was calculated according to the formula of Janssen and skeletal muscle mass index (AMI $1 / 4 \mathrm{AMM} /$ height in $\mathrm{m}^{2}$ ) was also calculated (26).

\section{Statistical analysis}

Quantitative variables that were normally distributed were expressed as the mean \pm standard deviation (SD), and quantitative variables that were not normally distributed were reported as the median and percentiles (P25-P75). ShapiroWilk's test verified the normal distribution of all parameters. Qualitative variables were reported as absolute and relative frequencies (\%). Global presentation of all subjects' baseline characteristics was performed and the undernourished subjects' characteristics were compared to well-nourished ones using a univariable analysis. Student's or Chi squared tests were therefore used. Logistic regression analysis was used to evaluate the factors associated with outcome. The data analyses were performed using STATISTICA 12 software. The results were considered statistically significant when 2 -tailed $\mathrm{p}$ values were less than 0.05 .

\section{Results}

\section{Population}

A total of 79 patients were enrolled prospectively. Mean age was $84.9 \pm 5.3$ years with a predominance of female gender (77.2\%). Before hospitalization, most patients lived at home $(92.4 \%)$. The Charlson co-morbidity index was $6.20 \pm 1.7$. Hospitalization was related to a history of fall in one-fifth of the patients. Number of drugs consumed was 7.8 \pm 4.9 . Autonomy for activity of daily level was moderate with a score of $15 \pm 6.3$. Short geriatric depression scale was in normal range $(0.96 \pm$ 1.2). Using MMA and the Glim criteria, a total of 21 (26.6\%) patients were found undernourished.

Table 2

TEE and EI according to nutritional status

\begin{tabular}{lccc}
\hline Population & $\begin{array}{c}\text { TEE } \\
\text { (kcal/kg/day) }\end{array}$ & $\begin{array}{c}\text { EI } \\
\text { (kcal/kg/day) }\end{array}$ & p \\
\hline Total & $25.4 \pm 4.2$ & $31.7 \pm 9.3$ & $<0.0001$ \\
Well-nourished & $24.4 \pm 3.7$ & $30.7 \pm 9.1$ & $<0.0001$ \\
Undernourished & $28.4 \pm 4.5$ & $34.6 \pm 9.2$ & 0.022 \\
\hline
\end{tabular}

TEE: Total Energy Expenditure; EI; Energy Intake 


\section{CLINICAL IMPACT OF NUTRITIONAL STATUS AND ENERGY BALANCE IN ELDERLY HOSPITALIZED PATIENTS}

Figure 1

Relationship between BMI and REE, TEE, EI

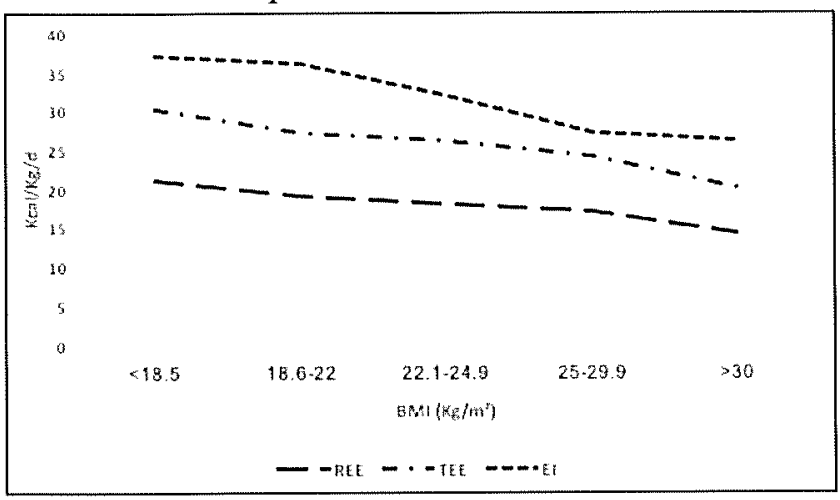

RRE: Rest Energy Expenditure; TEE: Total Energy Expenditure; EI: Energy Intake

\section{Nutritional status, energy needs and energy intake}

Mean BMI of the entire population was $24.2 \pm 5.1 \mathrm{~kg} / \mathrm{m}^{2}$. Eleven $(13.9 \%)$ patients had a BMI under $18.5 \mathrm{~kg} / \mathrm{m}^{2}$, and 13 (16.1\%) upper $30 \mathrm{~kg} / \mathrm{m}^{2}$. Mean TEE was $1556 \pm 259 \mathrm{kcal}$ and mean EI was $1990 \pm 484 \mathrm{kcal}$. Men had significantly higher energy needs than women $(1724 \pm 359 \mathrm{kcal}$ vs. $1509 \pm 203$ kcal, $p=0.0019)$. Energy needs were inversely correlated with
BMI $(\mathrm{R}=0.41, \mathrm{p}=0.0002)$ and ASMI $(\mathrm{R}=0.36, \mathrm{p}=0.0013)$. With the increase in BMIs, REE and TEE adjusted for body weight progressively decreased ( $\mathrm{p}<0.05$, for all) (Table 1, Figure 1). When adjusted by day, REE and TEE were higher in patients with the higher BMI ( $p<0.05$, for all). A similar observation was obtained with EI ( $p<0.05$, for all). Overall, energy needs and EI were weakly but significantly correlated $(R=0.22$; $\mathrm{p}=0.049$ ). EI was nevertheless significantly greater than energy needs (difference needs - intake $=-354 \pm 491 \mathrm{kcal} /$ day; $\mathrm{p}<0.0001$ ) (Table 2). This difference did not depend on BMI $(p=0.82)$, ASMI $(p=0.63)$, or the presence of undernutrition $(\mathrm{p}=0.33)$.

\section{Characteristics of undernourished patients}

A total of $21(26.6 \%)$ patients was found undernourished (Table 3). No significant differences were observed between groups for age, sex, Charlson score, and the presence of cognitive disorder ( $\mathrm{p}=\mathrm{NS}$ for all). Conversely, BMI, weight and ASMI ( $p<0.05$ for all) were lower in undernourished patients. In these patients, REE and TEE were also significantly lower compared to well-nourished patients (985 \pm 157 vs. $1124 \pm$ $176 \mathrm{kcal} / \mathrm{day}(\mathrm{p}=0.0025)$ and $1409 \pm 224 \mathrm{vs} .1607 \pm 252 \mathrm{kcal} /$ day) $(\mathrm{p}=0.0025)$ (Table 4). After adjustment for body weight, a reverse relationship was observed between undernutrition and

Table 3

Comparison between well- and undernourished patients (clinical data)

\begin{tabular}{|c|c|c|c|c|}
\hline & Total $n=79$ & Well-nourished $\mathrm{n}=58(73.4 \%)$ & Undernourished $\mathrm{n}=21(26.6 \%)$ & p \\
\hline Age (years) & $84.9 \pm 5.3$ & $84.4 \pm 5$ & $86.4 \pm 5.8$ & 0.14 \\
\hline Sex (women) & $61(77.2)$ & $47(77.6)$ & $16(76.2)$ & 0.23 \\
\hline Residence & & & & 0.19 \\
\hline - Home & $73(92.4)$ & $52(89.7)$ & $21(100)$ & \\
\hline - Nursing home & $6(7.6)$ & $6(10.3)$ & $0(0)$ & \\
\hline Comorbidity (Charlson) & $6.2 \pm 1.7$ & $6.3 \pm 1.6$ & $6 \pm 1.8$ & 0.28 \\
\hline Number of medications & $7.8 \pm 4.9$ & $8.3 \pm 3.4$ & $6.3 \pm 4.2$ & 0.04 \\
\hline Reason for hospitalisation & & & & 0.75 \\
\hline - Fall & $17(21.5)$ & $12(20.7)$ & $5(23.8)$ & \\
\hline - Neuro & $20(25.3)$ & $16(27.6)$ & $4(19)$ & \\
\hline - Digestive & $7(8.9)$ & $4(6.9)$ & $3(14.3)$ & \\
\hline - Cardiac/Pulmonary disease & $15(19.0)$ & $11(19.0)$ & $4(19.0)$ & \\
\hline - Osteoarticular disease & $12(15.5)$ & $10(17.2)$ & $2(9.5)$ & \\
\hline - Others & $8(10.1)$ & $5(8.6)$ & $3(14.3)$ & \\
\hline Edmonton & $8.8 \pm 2.4$ & $8.6 \pm 2.4$ & $9.4 \pm 2.4$ & 0.18 \\
\hline Cognitive disorder & $58(73.4)$ & $42(72.4)$ & $16(76.2)$ & 0.74 \\
\hline GDS & $0.96 \pm 1.2$ & $0.8 \pm 1.1$ & $1.4 \pm 1.6$ & 0.072 \\
\hline $\operatorname{ADLs}(/ 32)$ & $15 \pm 6.3$ & $15 \pm 6.6$ & $14 \pm 5.6$ & 0.36 \\
\hline Length of hospital stay (days) & $18.7 \pm 8$ & $17.8 \pm 6.7$ & $21.3 \pm 10.7$ & 0.089 \\
\hline
\end{tabular}

GDS: Geriatric Depression Scale; ADLs: Activities of Daily Level 
THE JOURNAL OF NUTRITION, HEALTH \& AGING

Table 4

BMI, energy needs and intake according to nutritional status

\begin{tabular}{|c|c|c|c|c|}
\hline & Total $n=79$ & Well-nourished $\mathrm{n}=58(73.4 \%)$ & Undernourishedn=21 $(26.6 \%)$ & $\mathbf{P}$ \\
\hline $\mathrm{BMI}\left(\mathrm{kg} / \mathrm{m}^{2}\right)$ & $24.2 \pm 5.1$ & $26 \pm 4.2$ & $20 \pm 3.9$ & $<0.0001$ \\
\hline$-<18.5$ & $11(13.9)$ & $0(0)$ & $11(13.9)$ & \\
\hline$-\geq 18.5-22$ & $15(19)$ & $8(13)$ & $7(33)$ & \\
\hline$-22.1-24.9$ & $20(25.3)$ & $19(32.8)$ & $1(4.8)$ & \\
\hline$-25-29.9$ & $20(25.3)$ & $18(31)$ & $2(9.5)$ & \\
\hline$-\geq 30$ & $13(16.1)$ & $13(22)$ & $0(0)$ & \\
\hline Weight (kg) & $62.4 \pm 13.6$ & $66.8 \pm 12.1$ & $50.2 \pm 8.7$ & $<0.0001$ \\
\hline $\operatorname{ASMI}\left(\mathrm{kg} / \mathrm{m}^{2}\right)$ & $7.9 \pm 1.6$ & $8.3 \pm 1.4$ & $6.7 \pm 1.6$ & $<0.0001$ \\
\hline \multicolumn{5}{|l|}{ REE (kcal) } \\
\hline - kcal/day & $1088 \pm 181$ & $1124 \pm 176$ & $985 \pm 157$ & 0.0025 \\
\hline$-\mathrm{kcal} / \mathrm{kg} / \mathrm{day}$ & $17.8 \pm 2.9$ & $17.1 \pm 2.6$ & $19.8 \pm 3.1$ & 0.0002 \\
\hline \multicolumn{5}{|l|}{ TEE } \\
\hline - kcal/day & $1556 \pm 259$ & $1607 \pm 252$ & $1408.5 \pm 224$ & 0.0025 \\
\hline$-\mathrm{kcal} / \mathrm{kg} / \mathrm{day}$ & $25.4 \pm 4.2$ & $24.4 \pm 3.7$ & $28.4 \pm 4.5$ & 0.0002 \\
\hline \multicolumn{5}{|l|}{ EI } \\
\hline - kcal/day & $1990 \pm 484$ & $1993.1 \pm 477.2$ & $1717.5 \pm 453.7$ & 0.024 \\
\hline - kcal/kg/day & $31.7 \pm 9.2$ & $30.7 \pm 9.1$ & $34.6 \pm 9.2$ & 0.094 \\
\hline
\end{tabular}

BMI: Body Mass Index; Appendicular Skeletal Mass Index (ASMD; REE: Rest Energy Expenditure; TEE: Total Energy Expenditure; EI: Energy Intake.

energy expenditure with lower values in well-nourished patients (REE: $17.1 \pm 2.6$ vs. $19.8 \pm 3.1 \mathrm{kcal} / \mathrm{kg} / \mathrm{day}, \mathrm{p}=0.0002$ ) and TEE ( $24.4 \pm 3.7$ vs. $28.4 \pm 4.5 \mathrm{kcal} / \mathrm{kg} / \mathrm{day}, \mathrm{p}=0.0002)$. Similar observations were made for EI.

\section{Outcome}

Length of hospital stay was $18.7 \pm 8$ days and no significant difference was observed according to the nutritional status (Table 3). Only one patient died during the hospitalization and most of them returned at home after the hospitalisation (65.8\%). At 1-year follow-up, 15 (19\%) patients died and $20(25.6 \%)$ were institutionalized. During this period, the rate of death was higher in older patients $(87.5 \pm 4.8$ vs. $84.3 \pm 5.3$ years; $\mathrm{p}=0.039)$, in men $(7 / 15,47 \%$ vs. $11 / 64,17 \% ; \mathrm{p}=0.035)$ and in undernourished patients $(9 / 15,80 \%$ vs. $12 / 64,19 \% ; \mathrm{p}=0.0025)$. BMI $\left(21.5 \pm 5.07 \mathrm{~kg} / \mathrm{m}^{2}\right.$ vs. $\left.24.8 \pm 4.9 \mathrm{~kg} / \mathrm{m}^{2} ; \mathrm{p}=0.022\right)$ and ASMI $\left(6.90 \pm 1.53 \mathrm{~kg} / \mathrm{m}^{2}\right.$ vs. $\left.8.1 \pm 1.5 \mathrm{~kg} / \mathrm{m}^{2} ; \mathrm{p}=0.0089\right)$ were significantly lower in patients who died. Multivariable logistic regression analysis, after adjustment for age, BMI, and ASMI, showed that male gender ( $O R=5.63(1.41-22.6)$; $\mathrm{p}=0.015)$ and undernutrition (OR=7.29 (1.87-28.4); $\mathrm{p}=0.0043)$ emerged as independently associated with death after 1-year. Institutionalized patients had a significantly lower ASMI (7.2 $\pm 1.4 \mathrm{~kg} / \mathrm{m}^{2}$ vs $\left.8.2 \pm 1.5 \mathrm{~kg} / \mathrm{m}^{2} ; \mathrm{p}=0.0088\right)$, a higher Edmonton score (11 (9-12) vs. $8(7-10) ; \mathrm{p}=0.0002)$ and ADLs (17 (12.5$21)$ vs. $13(9-16) ; p=0.0075)$ than non-institutionalized patients.
No other parameters (e.g., age, gender, BMI) emerged in the univariable analysis. On multivariable analysis, only ASMI (OR 0.59 (0.35-0.99), $\mathrm{p}=0.044$ ) and ADL (OR 1.14 (1.00-1.30), $\mathrm{p}=0.043)$ were significantly associated with institutionalization.

\section{Discussion}

In the present population of elderly patients hospitalised in a geriatric ward, the main results of our study can be summarized as follows: 1) the prevalence of undernutrition using the GLIM criteria was high, reaching approximatively one fourth of the patients, 2) the use of an enriched senior meal was associated with higher EI than required, regardless of the nutritional status, 3) energy requirements adjusted for body weight was higher in the low BMI category, 4) undernutrition was associated with increased 1 -year mortality but not with institutionalization.

\section{Undernutrition in elderly patients}

Undernutrition is common among older people and is often under diagnosed $(2,7)$. The prevalence of undernutrition varies by setting and is reported to be $3 \%$ among community dwelling older people, $6 \%$ among those attending outpatients and $8.7 \%$ among those receiving home care services, but with considerable heterogeneity between studies (27). Similarly, the prevalence of undernutrition (20-70\%) in hospitalized patients depends on the clinical context (28). In our study, $26.6 \%$ of 


\section{CLINICAL IMPACT OF NUTRITIONAL STATUS AND ENERGY BALANCE IN ELDERLY HOSPITALIZED PATIENTS}

the patients suffered from undernutrition, which was slightly lower than the frequency (39\%) derived from the recent pooled data analysis by Kaiser et al. (29). However, the comparison of our results on undernutrition prevalence, with the results of other published studies, is very difficult due to the use of different screening and assessment tools (GLIM criteria) and the specific populations analyzed. Numerous studies have identified undernutrition as an important predictive factor of in hospital mortality $(16,30)$ while other investigations find that undernutrition upon hospitalizations was only a predictive factor of mortality after hospital discharge (6). Our results confirmed and extended this latter observation by showing a higher probability of dying at 1-year follow-up in undernourished patients. Intriguingly, undernutrition was not associated with institutionalization during follow-up.

\section{Energy needs and nutritional status}

Determining the amount of energy used by the body provides significant insight into the nutritional status $(12,13)$. Our REE $(17.8 \mathrm{kcal} / \mathrm{kg} /$ day $)$ was slightly lower than the one recently reported by Gaillard et al. ( $20 \mathrm{kcal} / \mathrm{kg} /$ day) and Alix et al. $(18.5 \mathrm{kcal} / \mathrm{kg} / \mathrm{day})$ concerning elderly hospitalized patients (2, 7). However, their cohorts of patients were approximatively 10-year younger than ours, which extends the idea that REE may decrease with age (4). However, numerous factors may also contribute to this difference: the acute illness condition, the time elapse between admission and calorimetry ( 1 week in our study), the fat-free mass proportion, the residual low-grade inflammation, and the level of physical activity (decreased during hospitalization) $(2,27)$. As previously shown by our group and others, the nutritional status of elderly also influences their energy requirements because weight-adjusted REE increases in line with a decrease in $\operatorname{BMI}(2,12,13,28)$. So, the lower the BMI, the higher the weight-adjusted energy needs (30). Also, our undernourished patients had a lower weight, a lower BMI, a lower ASMI and a higher REE adjusted for body weight. All these relationships suggest that the ratio of REE to metabolically active tissue mass (brain, kidneys, heart, liver) is greater in magnitude among patients with lower weights (32). This hypothesis is somewhat supported by the observation of a positive correlation between muscular mass and BMIs $(\mathrm{p}<0.0001)$.

\section{Adequacy of energy needs and intake}

Older people have impaired ability to accurately regulate energy balance through adjustments in EI (33). Cumulative negative energy balance can be however harmful in these patients. As a result, the assessment of energy requirements and intake adequacy among elderly are thus important for disease prevention, health maintenance and program development (9). However, few studies with limited number of patients have compared energy requirements, as assessed by indirect calorimetry, and EI in elderly hospitalized patients $(2,7,16)$. In practice, minimal energy requirements are set according to current nutritional recommendations (REE 18-20+stress factor or $30 \mathrm{kcal} / \mathrm{kg}$ body weight in severely underweight patients). Despite this, poor intake is common in elderly hospitalized patients $(9,34)$. At CHU Liège, we have gradually moved from a "standard" strategy to a more "active" strategy, by increasing calorie intakes in our senior menu $(\simeq 30-35 \mathrm{kcal} / \mathrm{kg}$ body weight) and by offering a personalized approach patient by patient. Practically, all the staff and especially the nurses were educated about the importance of optimal dietary intake; they monitored and stimulated patients to eat meals and snacks offered. At the beginning of the hospitalization and when the EI was insufficient, the dietitian adapted the menu according to the tastes and the nutritional needs. The family was allowed to come during lunch to accompany the patient to either help or make the meal friendlier. Consequently, and contrasting with previous reports $(9,33,34)$, the EI was superior to the energy requirements (TEE, REE) in our cohort of patients. Also, EI was negatively correlated to BMI when expressed per $\mathrm{Kg}$ of body weight. EI was $\simeq 354 \mathrm{Kcal} /$ day superior to the estimated requirement (TEE was $1556 \pm 259 \mathrm{kcal} /$ day). This difference was not affected by the BMI, ASMI and presence of undernutrition. Whether our strategy might have affected the hospital outcome needs to be evaluated in a larger cohort of patients.

\section{Limitations}

Our results cannot be transposed to all geriatric hospitalized patients. The number of patients examined was low. Indeed, those with severe cognitive impairment, acute illness, uncontrolled heart or renal failure and cancer were excluded from this study. However, the advanced age of our patients, the hospital environment and the use of indirect calorimetry to measure energy expenditure represent important strengths of this study. EI was estimated by the proportion of nutriment intake and not by the weighing food method (9).

\section{Conclusion}

Undernutrition remains common in elderly patients hospitalized in a geriatric unit and is associated with increased 1-year mortality but not with institutionalization. These patients have higher energy requirements, which indicates that special attention is required to diagnose undernutrition. Interestingly, the use of a personalized enriched meal for seniors provided by qualified nurses could sufficiently cover the energy requirements of this population, at least at a distance from hospital admission. These data need to be confirmed in a larger cohort of patients.

Author contributions: SA, FB, JY R, OB, NP and SG have made substantial contributions to the conception, study design, data analysis and interpretation, and manuscript preparation. The final version of the publication was accepted by all authors.

Conflict of interest: We hereby declare that none of the contributing authors have any conflict of interest, including specific financial interests or relationships and affiliations relevant to the subject matter or materials discussed in the manuscript. 


\section{THE JOURNAL OF NUTRITION, HEALTH \& AGING}

Acknowledgments: The authors would like to thank J. Weber (MD) and G. Doupagne (MD) for their help in acquiring the data and N. Dardenne for her help in analysing the data.

Ethical Standards: All patients provided a written informed consent and the study was approved by the EC.

\section{References}

1. Leslie W, Hankey C. Aging, Nutritional Status and Health. Healthcare (Basel) 2015;3:648-58.

2. Gaillard C, Alix E, Salle A, Berrut G, Ritz P. Energy requirements in frail elderly people: a review of the literature. Clin Nutr 2007;26:16-24.

3. Ahmed T, Haboubi N. Assessment and management of nutrition in older people and its importance to health. Clin Interv Aging 2010;5:207-216.

4. Cox NJ, Ibrahim K, Sayer AA, Robinson SM, Roberts HC . Assessment and Treatment of the Anorexia of Aging: A Systematic Review. Nutrients 2019;11(1) DOI: $10.3390 /$ nul 1010144 .

5. Landi F, Picca A, Calvani R, Marzetti E. Anorexia of Aging: Assessment and Management. Clin Geriatr Med 2017;33: 315-323.

6. Lim SL, Ong KCB, Chan YH, Loke WC, Ferguson M, Daniels L. Malnutrition and its impact on cost of hospitalization, length of stay, readmission and 3-year mortality. Clin Nutr 2012;3:345-50.

7. Alix E, Berrut G, Bore M, Bouthier-Quintard F, Buia JM, Chlala A, Cledat Y, d'Orsay G, Lavigne C, Levasseur R, Mouzet JB, Ombredanne MP, Salle A, Gaillard C, Ritz P. Energy requirements in hospitalized elderly people. J Am Geriatr Soc. 2007;55:1085 9.

8. Vanderwee $K$, Clays E, Bocquaert I, Gobert $M$, Folens B, Defloor T. Malnutrition and Associated Factors in Elderly Hospital Patients: A Belgian Cross-Sectional, MultiCentre Study. Clin Nutr 2010;29: 469-76.

9. Gomes F, Schuetz P, Bounoure L, Austin P, Ballesteros-Pomar M, Cederholm T, Fletcher J, Laviano A, Norman K, Poulia KA, Ravasco P, Schneider SM, Stanga Z, Weekes CE, Bischoff SC. ESPEN guidelines on nutritional support for polymorbid internal medicine patients. Clin Nutr 2018;320187:336-353.

10. Wolff JL, Starfield B, Anderson G. Prevalence, expenditures, and complications of multiple chronic conditions in the elderly. Arch Intern Med 2002;162:2269-76.

11. Boullata J, Williams J, Cottrell F, Hudson L, Compher C. Accurate determination of energy needs in hospitalized patients. J Am Diet Assoc 2007;107:393-401.

12. Buckinx F, Paquot N, Fadeur M, Bacus L, Reginster JY, Allepaerts S, Petermans J, Biquet $S$, Bruyère $O$. Assessment of the energy expenditure of Belgian nursing home residents using indirect calorimetry. Nutrition 2019;57:12-16.

13. Buckinx F, Allepaerts S, Paquot N, Reginster JY, de Cock C, Petermans J, Bruyère $O$. Energy and Nutrient Content of Food Served and Consumed by Nursing Home Residents. J Nutr Health Aging 2017;21:727-732.

14. Mazzo R, Ribeiro FB, Vasques ACJ. Accuracy of predictive equations versus indirect calorimetry for the evaluation of energy expenditure in cancer patients with solid tumors - An integrative systematic review study. Clin Nutr ESPEN 2020;35:12-19.

15. Cederholm T, Jensen GL, Correia MITD, Gonzalez MC, Fukushima R, Higashiguch T, Baptista G, Barazzoni R, Blaauw R, Coats AJS, Crivelli AN, Evans DC, Gramlich L, Fuchs-Tarlovsky V, Keller H, Llido L, Malone A, Mogensen KM, Morley JE Muscaritoli M, Nyulasi I, Pirlich M, Pisprasert V, de van der Schueren MAE, Sitharm S, Singer P, Tappenden K, Velasco N, Waitzberg D, Yamwong P, Yu J, Van Gossum A, Compher C; GLIM Core Leadership Committee, GLIM Working Group. GLIM criteria for the diagnosis of malnutrition. A consensus report from the global clinical nutrition community J Cachexia Sarcopenia Muscle 2019;10:207-217.

16. Orlandoni P, Venturini C, Jukic Peladic N, Costantini A, Di Rosa M, Cola C Giorgini N, Basile R, Fagnani D, Sparvoli D, David S. Malnutrition upon Hospital Admission in Geriatric Patients: Why Assess It? Front Nutr 2017;4,50. DOI: 10.3389/ fnut.2017.00050.

17. Katz S. Assessing self-maintenance: activities of daily living, mobility, and instrumental activities of daily living $J$ Am Geriatr Soc 1983;31:721-7.

18. Tombaugh TN, McIntyre NJ. The mini-mental state examination: a comprehensive review. J Am Geriatr Soc 1992;40:922-35.

19. Clement JP, Nassif RF, Léger JM, Marchan F. Development and contribution to the validation of a brief French version of the Yesavage Geriatric Depression Scale. Encephale 1997;23:91-9.

20. Charlson ME, Pompei P, Ales KL, MacKenzie CR. A new method of classifying prognostic comorbidity in longitudinal studies: development and validation. J Chronic Dis 1987;40:373-83.

21. Rolfson DB, Majumdar SR, Tsuyuki RT, Tahir A, Rockwood K. Validity and reliability of the Edmonton Frail Scale. Age Ageing 2006;35:526-9.

22. La Table Belge de composition des aliments, 2007. http://www.nubel com/fr/table-decomposition-des-aliments.html.

23. Vellas B, Guigoz Y, Garry PJ, Nourhashemi F, Bennahum D, Lauque S, Albarede JL. The Mini Nutritional Assessment (MNA) and Its Use in Grading the Nutritional State of Elderly Patients. Nutrition 1999;15:116-22.

24. Elia M. Insights into energy requirements in disease. Public Health Nutr 2005;8:1037-

25. Bonnefoy M, Gilbert T, Normand S, Jauffret M, Roy P, Morio B, Cornu C, Roche S, Laville M. Energy Expenditure in Older People Hospitalized for an Acute Episode. Nutrients 2019;11(12). DOI: 10.3390/nul122946.

26. Janssen I, Heymsfield SB, Baumgartner RN, Ross R. Estimation of skeletal muscle mass by bioelectrical impedance analysis. J Appl Physiol 2000;89:465-71.

27. Cereda E, Pedrolli C, Klersy C, Bonardi C, Quarleri L, Cappello S, Turri A, Rondanelli M, Caccialanza R. Nutritional status in older persons according to healthcare setting: A systematic review and meta-analysis of prevalence data using MNA. Clin Nutr 2016;35:1282-1290.

28. Agarwal E, Miller M, Yaxley A, Isenring E. Malnutrition in the elderly: a narrative review. Maturitas 2013;76:296-302.

29. Kaiser MJ, Bauer JM, Rämsch C, Uter W, Guigoz Y, Cederholm T, Thoma DR, Anthony PS, Charlton KE, Maggio M, Tsai AC, Vellas B, Sieber CC. Min Nutritional Assessment International Group. Frequency of malnutrition in older adults: a multinational perspective using the mini nutritional assessment. J Am Geriatr Soc 2010;58:1734-8.

30. Sullivan DH, Sun S, Walls RC. Protein-energy undernutrition among elderly hospitalized patients. A prospective study. JAMA 1999;281:2013-9.

31. Carneiro IP, Elliott SA, Siervo M, Padwal R, Bertoli S, Battezzati A, Prado CM. Obesity Associated with Altered Energy Expenditure? Adv Nutr 2016;7:476-87.

32. Heymsfield SB, Gallagher D, Kotler DP, Wang Z, Allison DB, Heshka S. Bodysize dependence of resting energy expenditure can be attributed to nonenergetic homogeneity of fat-free mass. Am J Physiol Endocrinol Metab 2002;282:132-8.

33. Das SK, Moriguti JC, McCrory MA, Saltzman E, Mosunic C, Greenberg AS, Roberts SB. An underfeeding study in healthy men and women provides further evidence of impaired regulation of energy expenditure in old age. J Nutr 2001;131:1833-8.

34. A summary of selected new evidence relevant to NICE clinical guideline 32 'Nutrition support in adults: oral nutrition support, enteral tube feeding and parenteral nutrition 2006 [Internet]. London: National Institute for Health and Care Excellence (UK); 2013 http://www.ncbi.nlm.nih.gov/books/NBK551955/. 